\title{
Cycling, driving, and injuries
}

\section{Broadening the range of people who cycle}

In the 1960s, Dutch cities were increasingly car-focussed. Cycle trip share in Amsterdam fell from $80 \%$ in 1950 s to $20 \%$ in the 1970 s (van der Zee, 2015). Child traffic deaths were the catalyst to reduce car use and promote cycling (Wardlaw, 2014). Road travel deaths peaked in 1971 at 3,300, of whom more than 400 were children (van der Zee, 2015). Campaigners pioneered street closure days to allow children to play in the streets. Eventually, the 'woonerf' [homezone] was developed, followed by car-free Sundays. Nowadays, there are extensive networks of segregated cycle paths; more than a quarter of trips in the Netherlands are cycled, and almost two-fifths of trips in Amsterdam. However, in other countries, such as New Zealand, opposition to cycle lanes can be very vocal, particularly from local businesses (Field et al., 2018). We know that cyclists, like pedestrians, visit local businesses more frequently and, over a period of time, spend more money locally than drivers do (Mindell, 2015). A recent study has shown that increased cycling is associated with new businesses opening (Klemmer et al., 2018).

Compared with overall cycling, traffic-free cycle routes carry relatively more female, older, and ethnic minority cyclists for shopping trips; females on educational commutes; and younger and ethnic minority cycle commuters. Traffic-free routes have also been found to attract new cyclists from deprived areas and disproportionate numbers of novice cyclists from minority ethnic groups. Older cyclists, in particular want segregated cycle facilities as their priority, with other important factors being traffic density and an even surface (Van Cauwenberg et al., 2019a). In Chile, cycling for transport is more common among young adults and males; is used particularly by males from low socio-economic groups; but is used less than average by women from low socio-economic group (Aguilar-Farias et al., 2019, Editor's Choice). Some of the health and wellbeing benefits of cycling are also available to cycle passengers. Cycling without Age (https://cyclingwithoutage.org/) has branches in 42 countries, trying to bring cycling to all by using tricycle rickshaws to take frail people and those with dementia out for cycle rides.

After adjustment for demographic and socio-economic factors, including ethnicity and the presence of children and multiple motor vehicles at home, cycle commuting in two counties in the USA was associated with working in organisations with bike lockers, bike racks, locked rooms or cages, clothes storage, showers and workplace policies for bicycling to work (Porter et al., 2019). The authors point out that, being a cross-sectional study, these findings could be due to reverse causality, with people who want to commute by cycle searching for employers that at provide such facilities. An older study of traffic-free cycle routes had concluded that providing infrastructure is not sufficient by itself to increase cycling for travel (Jones, 2012), so it is perhaps the existence of facilities at every stage of the journey from home to an employee's desk or factory floor that is important. Another study reports that a short training session (2-4.5h) in Vancouver increased cycling for all purposes in the short-term but did not increase cycling for travel in the longer term (Sersli et al., 2019). The authors compare their findings with other studies where cycle training was effective (Johnson and Margolis, 2013) and discuss possible explanations. These could be due to the course itself, or training alone could be insufficient in the absence of appropriate infrastructure and if social norms about travel exclude cycling.

It is good to know that the bike share facilities in Chicago extend to poorer areas, which is not always the case (https://www.citylab.com/equity/2016/01/bike-share-poor-equity-transit/424656/; (Oates et al., 2017). However, bikeshare users in deprived areas of Chicago are generally exposed to higher 
levels of particulate pollution than those in more affluent areas (Qian and $\mathrm{Wu}, 2019)$. The response to this should be to improve air quality, not avoid cycling. The health benefits of physical activity and of being able to access jobs - greatly outweigh the harms from air pollution in all but the most extreme circumstances.

\section{The health of drivers}

We are receiving an increasing number of submissions concerning the health of professional drivers. While most of these manuscripts fit better in journals of occupational health, we are accepting a few. Professional drivers have a number of occupational hazards. Raised cardiovascular disease, related to sedentary behaviour, is well-known (Morris, and Raffle, 1954). High prevalence of other 'lifestyle' cardiovascular risk factors is also very common (Crizzle et al., 2017). Other problems include an increased risk of metabolic syndrome (Mabry et al., 2016) and musculo-skeletal pains (Senthanar and Bigelow, 2018; Serrano-Fernández et al., 2019). Bartel and colleagues suggest that ride-share taxi drivers have similar problems but these are exacerbated by the stress of the gigeconomy (Bartel et al., 2019). Given that Lyft and Uber have recently become publicly owned companies, one of our reviewers pondered whether share-holders have any concerns over the importance of drivers' health and work conditions? Fatigue and poor sleep also affect professional drivers' health adversely, with poor sleep being associated with a higher incidence of a crash in the last year (Kwon et al., 2019). Kwon and colleagues also found several factors related to risky driving by professional drivers. For example, drivers who were current smokers or drank alcohol were more likely to speed. Mental health is also affected by the stress of congestion in urban Iran, with impacts on family interactions, especially for the families of inner-city drivers (Nadrian et al., 2019).

While most papers in this journal focus on the impacts of transport on health, other papers consider how pre-existing health affects transport. For example, older drivers with poorer cognition pay less attention when driving (Ang et al., 2019). A study of drivers with autism spectrum disorders (ASD) found that they spend less time scanning and pay less visual attention to social stimuli. Although their driving is generally less risky, they had slower motor processing speed, possibly explaining difficulty in stopping in time at red lights (Ting Chee et al., 2019). Wickens et al. (2019) examined the long term driving outcomes among people who had conduct disorders as children. Conduct disorders generally manifest as violation of social norms and include aggressive behaviour towards other people, destruction of property, theft, and deceit. A range of adverse outcomes in adulthood have been reported (Fergusson et al., 2005), as has risky driving (McDonald et al., 2014). In the study reported in this issue, drivers with a history of conduct disorders had a $77 \%$ increased risk of having a car crash in the previous year, even after adjusting for other factors (Wickens et al., 2019).

Nyberg and colleagues report that drivers whose licences are withdrawn because of visual problems have a range of negative consequences. These are not only practical, related to the loss of personal car use in a car-dependent society, but also affect their wellbeing as they view this as unfair (Nyberg et al., 2019). Another study of former drivers, who had decided for themselves to stop driving but had not planned their future travel modes, also found they reported substantial restrictions on their daily lives (Shope et al., 2019).

Van Cauwenberg and colleagues (in this issue) show that older people who cycle - whether using conventional or electric cycles - have larger social spaces, regardless of their health status (Van Cauwenberg et al., 2019b). The reasons for using, or indeed providing, e-bikes continue to expand. A local government in Wales has piloted a programme to encourage 'hard to reach' adults to cycle, using e-bikes as the introduction to cycling. They are now starting a pilot scheme to encourage overweight children to be more active by using loaned e-bikes for long, supervised journeys on 
roads, with the aim of increasing physical activity, reducing sedentary behaviours, improving mental health, and reducing body mass index levels (https://www.transportxtra.com/publications/localtransport-today/news/59566/council-to-put-obese-kids-on-e-bikes). This looks like a longitudinal study waiting to be funded!

\section{Road travel injuries}

The International Road Assessment Partnership (iRAP) has developed a star rating system for roads to assess the safety of individual roads for each type of user, with 1 star being the most dangerous and 5 star providing the best protection. iRAP data show that, worldwide, $88 \%$ of pedestrians and $86 \%$ of cyclists travel on roads rated as only 1- or 2-star, compared with $44 \%$ of car drivers (https://www.irap.org/3-star-or-better/). Globally, 70\% of roads have no pavements [sidewalks]; $89 \%$ have no pedestrian crossings; and $94 \%$ have no facilities for cyclists (https://www.irap.org/2019/04/new-case-study-available-5-star-cities-for-all-road-users/). iRAP is reported as stating that in the absence of segregated infrastructure, no road can be rated as 5 -star unless the speed limit it $30 \mathrm{~km} / \mathrm{h}$ or less (http://www.20splenty.org/dft cwis). A number of other international bodies have also called for $30 \mathrm{~km} / \mathrm{h}$ or $20 \mathrm{mph}$ speed limits to reduce both crashes and the severity of injuries (World Health Organization, 2017). When motor vehicles are travelling at $30 \mathrm{~km} / \mathrm{h}$ or below, $90 \%$ of pedestrians will survive an impact. At speeds of $45 \mathrm{~km} / \mathrm{h}$ [ $28 \mathrm{mph}$ ], this falls to less than 50\% (Peden and World Health Organization, 2004). Speed limits need to be set appropriately but, just as importantly, they also need to be enforced (European Transport Safety Council, 2019).

Earlier this year, we published a paper that disputes the 'safety in numbers' causation theory (Marshall and Ferenchak, 2019). While it is well accepted that the more pedestrians or cyclists there are, the lower the injury and fatality rates are for these travellers (Elvik and Bjørnskau, 2017), there is less certainty about why this is the case. It is likely that the main explanation is that the conditions that encourage more people to cycle are also those that reduce road danger, as has been argued for pedestrians (Bhatia and Wier, 2011). The data analysed by Marshall and Ferenchak suggests that road danger reduction for cyclists is associated with higher prevalence of cycle facilities, with separated, protected cycle lanes particularly important. Crucially, they found that higher intersection density, which is itself associated with lower speed environments in more compact areas, was strongly related to reduced road danger for all types of road users, not just for cyclists. Worryingly, they also found that gentrification, namely an increasing proportion of non-Hispanic white residents in these US cities, was strongly associated with road danger reduction (Marshall and Ferenchak, 2019).

Thompson and colleagues have used agent-based modelling to demonstrate a potential causal route from increased numbers to increased safety. They postulate that increased experience by drivers of seeing cyclists on the road leads to expectation of there being cyclists, thus altering drivers' behaviour (Thompson et al., 2016). One feature they cite as important but discuss little is that drivers perceive cyclists as legitimate users of the road. My theory is that as cyclist numbers increase, the number of drivers who know people who cycle increases exponentially, thus converting 'cyclists' from 'them' to 'us'. This 'Mindell' theory is based solely on personal anecdote - the large number of acquaintances who have told me over the past 15 years that they are now more careful when driving past a cyclist in case it is my husband or me!

Injuries on public transport tend to garner far less attention than those in private motor vehicles and non-motorised modes, probably because the numbers and rates are far lower, but they do occur (Kendrick et al., 2015). Elvik has estimated the risks of falling inside a public transport vehicle as 0.2- 
0.3 per million passenger $\mathrm{km}$ and of falls when boarding or alighting as 0.8-1.7 per million passengers (Elvik, 2019). A recent paper characterised the demographics and injuries sustained when boarding or alighting compared with when the bus was travelling (Siman-Tov et al., 2019); this issue includes a paper that goes a step further. Silvano and Ohlin have shown that the people most vulnerable to injuries as bus passengers during a hard acceleration by the driver differ from those most vulnerable during hard braking. In general, hard acceleration occurs soon after passengers board, therefore older people are more at risk. Falls due to hard braking tend to occur during the journey, affecting younger people more (Silvano and Ohlin, 2019). While the bus system in Dunedin has many faults, such as few routes and low frequency, the drivers do always wait for all passengers (of any age) to be seated before they move off.

Meanwhile, a study in British Columbia shows substantial mismatches between police records and hospital admissions of injured drivers. Police did not attend one-third of crashes that resulted in hospital admission of the driver and classified only one-third of hospitalised drivers as having a major injury, but half the drivers deemed by police to have serious injuries were not admitted to hospital (Brubacher et al., 2019). This is unsurprising and is not necessarily an indictment of police, as they are not trained to assess injury severity. Data is also an issue in Pakistan, where police and emergency response data greatly underestimated road travel injuries as detected by a survey of the general public (Younis et al., 2019). Even where data are accurate for an initial road travel injury, follow-up and treatment are often lacking. Among those surviving more than 24 months after road travel injury, people in Victoria, Australia, living in non-metropolitan areas had a lower prevalence of reported problems with mental health or pain. Regardless of location, only around half had received treatment for these through the state system (Giummarra et al., 2019).

\section{Journal news}

We currently have calls for submissions to a special issue on Travel, health, and wellbeing (https://www.journals.elsevier.com/journal-of-transport-and-health/call-for-papers/travel-healthwell-being) and another on Transport and health in New Zealand

(https://www.journals.elsevier.com/journal-of-transport-and-health/call-for-papers/transport-andhealth-in-new-zealand). This issue includes a paper covering both of these topics, exploring why cycle commuters generally report the highest satisfaction levels for their commute. The four key benefits reported were: control and reliability of arrival time; enjoyment of the surroundings; feeling better because of undertaking moderate exercise; and more opportunities for social interaction (Wild and Woodward, 2019). Their findings will not surprise those who enjoy cycling (although the last did surprise me in relation to cycling for travel) but it is important to have good quality evidence about the positive effects of cycling, given the overwhelming media attention to the risks of injury (Macmillan et al., 2016) and to air pollution.

One change you will see from this volume onwards is that journal articles will no longer have page numbers but instead will have article numbers. This change is to enable us to publish accepted articles even faster while still collating them by article and issue type. This volume includes the bulk of the articles that form the virtual special issue (VSI) on Transport and Health in Latin America; the rest were in volume 13 or will be published in volume 15 . Another editorial addresses some of the issues raised in these papers (Sagaris, 2019). The paper on transport cycling in Chile is the Editor's Choice paper for volume 14 (Aguilar-Farias et al., 2019). 


\section{References}

Aguilar-Farias, N., Cortinez-O'Ryan, A., Chandia-Poblete, D., Heesch, K.C., 2019. Prevalence and correlates of transport cycling in Chile: Results from 2014 to 2015 national surveys. J. Transp. Health 14, 100594. https://doi.org/10.1016/j.jth.2019.100594 (Editor's Choice)

Ang, B.H., Chen, W.S., Lee, S.W., 2019. The Malay Manchester Driver Behaviour Questionnaire: A cross-sectional study of geriatric population in Malaysia. J. Transp. Health 14, 100573. https://doi.org/10.1016/j.jth.2019.100573

Bartel, E., MacEachen, E., Reid-Musson, E., Meyer, S.B., Saunders, R., Bigelow, P., Kosny, A., Varatharajan, S., 2019. Stressful by design: Exploring health risks of ride-share work. J. Transp. Health 14, 100571. https://doi.org/10.1016/j.jth.2019.100571

Bhatia, R., Wier, M., 2011. "Safety in Numbers" re-examined: Can we make valid or practical inferences from available evidence? Accid. Anal. Prev. 43, 235-240. https://doi.org/10.1016/j.aap.2010.08.015

Brubacher, J.R., Chan, H., Erdelyi, S., 2019. Injury severity in police collision reports correlates poorly with requirement for hospital admission. J. Transp. Health 14, 100606. https://doi.org/10.1016/j.jth.2019.100606

Crizzle, A.M., Bigelow, P., Adams, D., Gooderham, S., Myers, A.M., Thiffault, P., 2017. Health and wellness of long-haul truck and bus drivers: A systematic literature review and directions for future research. J. Transp. Health 7, 90-109. https://doi.org/10.1016/j.jth.2017.05.359

Elvik, R., 2019. Risk of non-collision injuries to public transport passengers: Synthesis of evidence from eleven studies. J. Transp. Health 13, 128-136. https://doi.org/10.1016/j.jth.2019.03.017

Elvik, R., Bjørnskau, T., 2017. Safety-in-numbers: A systematic review and meta-analysis of evidence. Saf. Sci. 92, 274-282. https://doi.org/10.1016/j.ssci.2015.07.017

European Transport Safety Council, 2019. Managing speed in Europe (No. PIN Flash Report 36). ETSC, Brussels.

Fergusson, D., Horwood, J., Ridder, E., 2005. Show me the child at seven: the consequences of conduct problems in childhood for psychosocial functioning in adulthood. J Child Psychol Psychiatry 46, 837-849.

Field, A., Wild, K., Woodward, A., Macmillan, A., Mackie, H., 2018. Encountering bikelash: Experiences and lessons from New Zealand communities. J. Transp. Health 11, 130-140. https://doi.org/10.1016/j.jth.2018.10.003

Giummarra, M.J., Amoh-Gyimah, R., Saberi, M., Gabbe, B.J., 2019. Geographic variations in reported and treated pain and mental health problems in the first two years after transport-related major trauma. J. Transp. Health 14, 100581. https://doi.org/10.1016/j.jth.2019.100581

Johnson, R., Margolis, S., 2013. A review of the effectiveness of adult cycle training in Tower Hamlets, London. Transp. Policy 30, 254-261. https://doi.org/10.1016/j.tranpol.2013.09.005

Jones, T., 2012. Getting the British back on bicycles-The effects of urban traffic-free paths on everyday cycling. Transp. Policy 20, 138-149. https://doi.org/10.1016/j.tranpol.2012.01.014

Kendrick, D., Drummond, A., Logan, P., Barnes, J., Worthington, E., 2015. Systematic review of the epidemiology of non-collision injuries occurring to older people during use of public buses in high income countries. J. Transp. Health 2, 394-405. https://doi.org/10.1016/j.jth.2015.06.002

Klemmer, K., Brandt, T., Jarvis, S., 2018. Isolating the effect of cycling on local business environments in London. PLOS ONE 13, e0209090. https://doi.org/10.1371/journal.pone.0209090

Kwon, S., Kim, H., Kim, G.S., Cho, E., 2019. Fatigue and poor sleep are associated with driving risk among Korean occupational drivers. J. Transp. Health 14, 100572. https://doi.org/10.1016/j.jth.2019.100572

Mabry, J.E., Hosig, K., Hanowski, R., Zedalis, D., Gregg, J., Herbert, W.G., 2016. Prevalence of metabolic syndrome in commercial truck drivers: A review. J. Transp. Health 3, 413-421. https://doi.org/10.1016/j.jth.2016.06.012 
Macmillan, A., Roberts, A., Woodcock, J., Aldred, R., Goodman, A., 2016. Trends in local newspaper reporting of London cyclist fatalities 1992-2012: the role of the media in shaping the systems dynamics of cycling. Accid. Anal. Prev. 86, 137-145. https://doi.org/10.1016/j.aap.2015.10.016

Marshall, W.E., Ferenchak, N.N., 2019. Why cities with high bicycling rates are safer for all road users. J. Transp. Health 13, 100539. https://doi.org/10.1016/j.jth.2019.03.004

McDonald, C.C., Sommers, M.S., Fargo, J.D., 2014. Risky driving, mental health, and healthcompromising behaviours: risk clustering in late adolescents and adults. Inj. Prev. 20, 365372. https://doi.org/10.1136/injuryprev-2014-041150

Mindell, J.S., 2015. Active travel is (generally) good for health, the environment and the economy. J. Transp. Health 2, 447-448. https://doi.org/10.1016/j.jth.2015.10.006

Morris, J.N., Raffle, P.A.B., 1954. Coronary heart disease in transport workers. Br. J. Ind. Med. 11, 260.

Nadrian, H., Taghdisi, M.H., Pouyesh, K., Khazaee-Pool, M., Babazadeh, T., 2019. “I am sick and tired of this congestion": Perceptions of Sanandaj inhabitants on the family mental health impacts of urban traffic jam. J. Transp. Health 14, 100587. https://doi.org/10.1016/j.jth.2019.100587

Nyberg, J., Strandberg, T., Berg, H.-Y., Aretun, A., 2019. Welfare consequences for individuals whose driving licenses are withdrawn due to visual field loss: A Swedish example. J. Transp. Health 14, 100591. https://doi.org/10.1016/j.jth.2019.100591

Oates, G.R., Hamby, B.W., Bae, S., Norena, M.C., Hart, H.O., Fouad, M.N., 2017. Bikeshare Use in Urban Communities: Individual and Neighborhood Factors. Ethn. Dis. 27, 303. https://doi.org/10.18865/ed.27.S1.303

Peden, M.M., World Health Organization (Eds.), 2004. World report on road traffic injury prevention. World Health Organization, Geneva.

Porter, A.K., Kohl, H.W., Salvo, D., 2019. Dose-response association of workplace facilities and policies with commuter bicycling among adults. J. Transp. Health 14, 100603. https://doi.org/10.1016/j.jth.2019.100603

Qian, X., Wu, Y., 2019. Assessment for health equity of PM2.5 exposure in bikeshare systems: The case of Divvy in Chicago. J. Transp. Health 14, 100596. https://doi.org/10.1016/j.jth.2019.100596

Sagaris, L., 2019. Gender, transport and health studies open new horizons for planning. JTH 14.

Senthanar, S., Bigelow, P.L., 2018. Factors associated with musculoskeletal pain and discomfort among Canadian truck drivers: A cross-sectional study of worker perspectives. J. Transp. Health 11, 244-252. https://doi.org/10.1016/j.jth.2018.08.013

Serrano-Fernández, M.-J., Boada-Grau, J., Robert-Sentís, L., Vigil-Colet, A., 2019. Predictive variables for musculoskeletal problems in professional drivers. J. Transp. Health 14, 100576. https://doi.org/10.1016/j.jth.2019.100576

Sersli, S., Scott, N., Winters, M., 2019. Effectiveness of a bicycle skills training intervention on increasing bicycling and confidence: A longitudinal quasi-experimental study. J. Transp. Health 14, 100577. https://doi.org/10.1016/j.jth.2019.100577

Shope, J.T., Begg, D., Brookland, R., 2019. Older former drivers' health, activity, and transport in New Zealand. J. Transp. Health 14, 100559. https://doi.org/10.1016/j.jth.2019.04.005

Silvano, A.P., Ohlin, M., 2019. Non-collision incidents on buses due to acceleration and braking manoeuvres leading to falling events among standing passengers. J. Transp. Health 14, 100560. https://doi.org/10.1016/j.jth.2019.04.006

Siman-Tov, M., Radomislensky, I., Marom, I., Kapra, O., Peleg, K., Bahouth, H., Becker, A., Jeroukhimov, I., Karawani, I., Kessel, B., Klein, Y., Lin, G., Merin, O., Bala, M., Mnouskin, Y., Rivkind, A., Shaked, G., Sivak, G., Soffer, D., Stein, M., Weiss, M., 2019. A nation-wide study on the prevalence of non-collision injuries occurring during use of public buses. J. Transp. Health 13, 164-169. https://doi.org/10.1016/j.jth.2019.03.019 
Thompson, J., Savino, G., Stevenson, M., 2016. A model of behavioural adaptation as a contributor to the safety-in-numbers effect for cyclists. Transp. Res. Part Policy Pract. 85, 65-75. https://doi.org/10.1016/j.tra.2015.12.004

Ting Chee, D.Y., Yeung Lee, H., Patomella, A.-H., Falkmer, T., 2019. The visual search patterns of drivers with Autism Spectrum Disorders in complex driving scenarios. J. Transp. Health 14, 100597. https://doi.org/10.1016/j.jth.2019.100597

Van Cauwenberg, J., De Bourdeaudhuij, I., Clarys, P., De Geus, B., Deforche, B., 2019a. Older adults' environmental preferences for transportation cycling. J. Transp. Health 13, 185-199. https://doi.org/10.1016/j.jth.2019.03.014

Van Cauwenberg, J., Schepers, P., Deforche, B., de Geus, B., 2019b. Differences in life space area between older non-cyclists, conventional cyclists and e-bikers. J. Transp. Health 14, 100605. https://doi.org/10.1016/j.jth.2019.100605

van der Zee, R., 2015. How Amsterdam became the bicycle capital of the world. The Guardian.

Wardlaw, M.J., 2014. History, risk, infrastructure: perspectives on bicycling in the Netherlands and the UK. J. Transp. Health 1, 243-250. https://doi.org/10.1016/j.jth.2014.09.015

Wickens, C.M., Mann, R.E., Ialomiteanu, A.R., Vingilis, E., Seeley, J., Erickson, P., Kolla, N.J., 2019. The association of childhood symptoms of conduct disorder and collision risk in adulthood. J. Transp. Health 13, 33-40. https://doi.org/10.1016/j.jth.2019.03.007

Wild, K., Woodward, A., 2019. Why are cyclists the happiest commuters? Health, pleasure and the ebike. J. Transp. Health 14, 100569. https://doi.org/10.1016/j.jth.2019.05.008

World Health Organization, 2017. Managing speed. WHO, Geneva.

Younis, M.W., Batool, Z., Bukhari, M., Rehman, Z. ur, Shahzad, S., Rehman, A. ur, Khan, A.H., Yasin, M., Irfan, M., Ali, M.S., 2019. Pattern of underreporting of Road Traffic Injuries (RTIs): An investigation of missing burden of RTIs in Pakistan. J. Transp. Health 14, 100575. https://doi.org/10.1016/j.jth.2019.100575 